\title{
Comparison of HIPWAC and Mars Express SPICAM observations of ozone on Mars 2006-2008 and variation from 1993 IRHS observations
}

\author{
by \\ Kelly E. Fast ${ }^{1}$, Theodor Kostiuk ${ }^{1}$, \\ Planetary Systems Laboratory, Code 693 \\ NASA Goddard Space Flight Center \\ Greenbelt, Maryland 20771 \\ Franck Lefèvre \\ LATMOS \\ CNRS, UPMC Univ. Paris 06 \\ 75005 Paris, France
}

\author{
Tilak Hewagama*, Timothy A. Livengood ${ }^{*}$, Juan D. Delgado $^{* 1 / 2}$ \\ Department of Astronomy \\ University of Maryland \\ College Park, Maryland 20742-2421 \\ John Annen ${ }^{1}$, \\ Planetary Systems Laboratory, Code 693 \\ NASA Goddard Space Flight Center \\ Greenbelt, Maryland 20771 \\ Guido Sonnabend ${ }^{1}$ \\ 1. Physikalisches Institut \\ Universität zu Köln \\ Zuilpicher Str. 77 \\ 50937 Köln, Germany
}

"Also at Planetary Systems Laboratory, Code 693, NASA Goddard Space Flight Center, Greenbelt, Maryland 20771

1 Visiting Astronomer at the Infrared Telescope Facility, which is operated by the University of Hawaii under Cooperative Agreement no. NCC 5-538 with the National Aeronautics and Space Administration, Science Mission Directorate, Planetary Astronomy Program.

2 Current address: Universiteit Leiden, Leiden Observatory, J.H. Oort Building, Niels Bohrweg 2, Room 460, NL-2333 CA Leiden, The Netherlands.

$\begin{array}{rc}\text { abstract: } & 1 \text { page } \\ \text { manuscript: } & 19 \text { pages } \\ \text { tables } & 2 \\ \text { ure captions: } & 3 \text { pages } \\ \text { figures: } & 6\end{array}$


Running Title: HIPWAC and SPICAM observations of ozone on Mars

$\begin{array}{ll}\text { Correspondence Address: } & \begin{array}{l}\text { Kelly Fast } \\ \text { Code 693 NASA/GSFC } \\ \text { Greenbelt, MD 20771 }\end{array} \\ & 301-286-7689 \\ \text { Phone: } & 301-286-1683 \\ \text { Fax: } & \text { Kelly.E.Fast@ nasa.gov } \\ \text { E-mail: } & \end{array}$




\begin{abstract}
Ozone is a tracer of photochemistry in the atmosphere of Mars and an observable used to test predictions of photochemical models. We present a comparison of retrieved ozone abundances on Mars using ground-based infrared heterodyne measurements by NASA Goddard Space Flight Center's Heterodyne Instrument for Planetary Wind And Composition (HIPWAC) and space-based Mars Express Spectroscopy for the Investigation of the Characteristics of the Atmosphere of Mars (SPICAM) ultraviolet measurements. Ozone retrievals from simultaneous measurements in February 2008 were very consistent $(0.8 \mu \mathrm{m}$-atm), as were measurements made close in time (ranging from $<1$ to $>8 \mu \mathrm{m}$-atm) during this period and during opportunities in October 2006 and February 2007. The consistency of retrievals from the two different observational techniques supports combining the measurements for testing photochemistry-coupled general circulation models and for investigating variability over the long-term between spacecraft missions. Quantitative comparison with ground-based measurements by NASA/GSFC's Infrared Heterodyne Spectrometer (IRIS) in 1993 reveals 2 4 times more ozone at low latitudes than in 2008 at the same season, and such variability was not evident over the shorter period of the Mars Express mission. This variability may be due to cloud activity.
\end{abstract}

Keywords: Mars, Atmosphere; Infrared Observations; Photochemistry; Spectroscopy; Abundances, Atmospheres 


\section{INTRODUCTION}

Ozone $\left(\mathrm{O}_{3}\right)$ is an important tracer of photochemistry in the atmosphere of Mars. It is destroyed by the odd hydrogen products of water photolysis that actively participate in the chemistry of the Martian atmosphere, including the catalytic reformation of carbon dioxide. Ozone therefore provides a probe of such species and their chemistry, and ozone has been employed extensively as an observable with which to test predictions of photochemical models. Increasingly complex photochemistry-coupled general circulation models [e.g., Lefèvre et al. 2004, 2008] require measurements of spatial, vertical, temporal and seasonal ozone variations in order to test their predictions and broaden the overall understanding of the chemistry and dynamics of the Martian atmosphere.

Currently, the Spectroscopy for the Investigation of the Characteristics of the Atmosphere of Mars (SPICAM) instrument on Mars Express [Bertaux et al. 2000] and the Mars Color Imager (MARCI) instrument on the Mars Reconnaissance Orbiter [Malin et al. 2001] are monitoring ozone abundance in the ultraviolet from Mars orbit. Such continuous ozone observations from orbit are the first since those of Mariner 9 in 197172 [e.g., Lane et al. 1973]. During the 33 years in between, and other than the brief observations by Mars 5 in 1974 [Krasnopolsky et al, 1975] and by Phobos 2 in 1989 [Blamont and Chassefiere 1993], near-Earth observations of ozone were the only sources of information for modelers. The Hubble Space Telescope Faint Object Spectrograph provided ultraviolet observations of ozone on Mars from Earth orbit [Clancy et al. 1996 , 1999]. Ground-based observations of $\mathrm{O}_{2}(\Delta)$ dayglow emission indirectly probed highaltitude ozone abundance [Novak et al. 2002, Krasnopolsky 2003, 2007]. Ground-based 
infrared heterodyne spectroscopy directly probed the ozone column down to the surface of Mars [Espenak et al. 1991, Fast et al. 2006a].

Earth-based observations, in addition to providing important observations for atmospheric modelers, fill in gaps between spacecraft missions of finite duration and connect those missions by placing their measurements in the context of long-term behavior. Earth-based measurements complement spacecraft observations by expanding spatial and temporal coverage. Earth-based instrumentation also offers capabilities that might not be represented on one particular mission such as increased spectral resolution and wavelength coverage. For these reasons, it is important to take advantage of opportunities to combine and compare Earth-based and Mars orbit-based measurements in order to check the consistency of retrieved physical parameters and to maximize science return through increased sampling. Properties such as year-to-year variability measured by different techniques cannot be reliably quantified unless those techniques undergo some sort of consistency check, such as simultaneous measurements. In this paper, ozone retrievals from ground-based infrared heterodyne measurements of 9.5 and $9.7 \mu \mathrm{m}$ ozone absorption features are compared with those from Mars Express SPICAM ultraviolet measurements of the $200-330 \mathrm{~nm}$ Hartley band. Simultaneous measurements in 2008 are compared to show consistency of retrievals. Contemporaneous measurements (within a few hours to a few days) on three occasions (Table 1) are examined and differences explored in the context of topography, dynamics, and temporal variability. The comparison of 2008 measurements is then extended to infrared heterodyne measurements made at the same season in 1993 in order to examine longterm variability. 
Infrared and ultraviolet techniques are quite different. Infrared (IR) heterodyne spectroscopy (Kostiuk 1994) is the only technique that can directly measure fullyresolved line shapes of Martian atmospheric ozone features from the surface of the Earth. The very high spectral resolving power $\left(N \Delta \lambda>10^{6}\right)$ makes the measurement of Martian ozone absorption features in the $9 \mu \mathrm{m}$ region possible when they are Doppler-shifted away from their telluric counterparts into spectral regions of higher atmospheric transmittance. Measurements of individual ozone absorption line shapes are made against the infrared-emitting surface of Mars, and are not strongly sensitive to normal amounts of dust in the atmosphere. They probe the entire atmospheric column with greatest sensitivity below $-20 \mathrm{~km}$. The fully-resolved line shapes depend on the abundance and vertical distribution of ozone and the local atmospheric and surface temperature. Ultraviolet (UV) measurements of ozone must be made beyond Earth's atmosphere. Incoming solar ultraviolet radiation is backscattered by the Martian surface and by molecules, dust, and aerosols in the atmosphere, and is absorbed across the Hartley band wavelengths. The ozone column abundance that produces the broad absorption feature can be retrieved using models of atmospheric scattering based on other observations. Ultraviolet spectroscopy is more sensitive to dust and aerosols than infrared, but has higher sensitivity to ozone at higher altitudes, and limb measurements from spacecraft can probe the vertical distribution of the high altitude $(>10-20 \mathrm{~km})$ ozone profile [e.g. Lebonnois et al. 2006].

Infrared heterodyne measurements of ozone made at a variety of Martian seasons between 1988 and 2003 were presented by Espenak et al. [1991] and by Fast et al. [2006a]. Those were compared to subsequent Mars Express SPICAM UV nadir 
measurements of ozone made at similar Martian seasons by Perrier et al. [2006] and to the predictions of three-dimensional photochemical models by Lefèvre et al. [2004, 2008] and Fast et al. [2006b]. Here, we present IR heterodyne measurements of ozone made on three occasions (Table 1) since the start of the Mars Express (MEX) mission and compare the ozone abundances retrieved to those obtained simultaneously and contemporaneously by SPICAM. We examine the consistency of these retrievals that adopt techniques from different regions of the electromagnetic spectrum, with different sensitivities to the ozone profile, spectral resolution and retrieval techniques. We then compare the 2008 results to seasonally similar IR heterodyne observations from 1993 and examine possible reasons for apparent variability between the two periods.

\section{OBSERVATIONS AND DISCUSSION}

Infrared heterodyne measurements of ozone presented here were made with NASA Goddard Space Flight Center's Heterodyne Instrument for Planetary Wind And Composition (HIPWAC) at the NASA Infrared Telescope Facility (IRTF) on Mauna Kea, Hawai' $i$. At IRTF, the $\sim 1$ " instrumental beam covers $\sim 10^{\circ}$ of Martian latitude in most cases $\left(-15^{\circ}\right.$ at high latitudes). Pointing is maintained at a constant Mars local time, and each spectrum tends to cover $\sim 10^{\circ}-40^{\circ}$ of longitude on Mars.

\section{Approximate position of Table 1}

Observations of ozone with HIPWAC have been made on three occasions since the start of the MEX mission and the accompanying nadir UV observations of ozone by SPICAM. Details of the HIPWAC observations are given in Table 1. Ozone absorption 
lines were measured at 9.5 and $9.7 \mu \mathrm{m}$. An absorption feature of $\mathrm{CO}_{2}$ was present in the bandpass for all of the observations, providing simultaneous measurement of local temperature from the absorption line wings (Fig. 1). Analysis of the Martian components of the observed spectra was performed using the beam-integrated radiative transfer analysis program BEAMINT [Hewagama et al. 2008]. The terrestrial components of the spectra were modeled simultaneously through calls to the GENLN2 radiative transfer program [Edwards 1992]. A HIPWAC spectrum acquired in 2008 with terrestrial contribution modeled and removed and the spectral sidebands decoupled is given in Fig. 1. Additional information on HIPWAC observations and on ozone retrieval techniques is given by Fast [2005] and Fast et al. [2006a], and SPICAM ozone retrieval techniques are detailed by Perrier et al. [2006].

Approximate position of Figure 1

In making the comparison between ozone retrievals from IR and UV observations, the place to start is with available simultaneous measurements. Such measurements were possible in February 2008 at $L_{S}=35^{\circ}$ (northern mid-spring) when HIPWAC observations were coordinated with SPICAM nadir measurements of ozone. Mars Express orbital passes took place over longitudes that were visible from Earth at times when Mars was accessible from IRTF and when SPICAM was operating. The observed aspect geometry and all ozone abundances retrieved by HIPWAC are given in Fig. 2, with abundances ranging from $<1 \mu$ m-atm at some low-latitude and southern locations up to $\sim 8 \mu \mathrm{m}-\mathrm{atm}$ at $60^{\circ} \mathrm{N}$. The orbit of MEX placed the nadir operation of 
SPICAM close to the limb of Mars as viewed from Earth (Fig. $2 a$, solid line) making simultaneous measurements possible at lower latitudes. A target latitude of $20^{\circ} \mathrm{N}$ at 14:00 Mars local time was chosen for simultaneous observations by HIPWAC (with the instrumental beam covering the MEX local time of 14:30), and measurements at other latitudes were made between 11:40 and 14:00 Mars local time. The atmosphere was relatively clear of dust as indicated by HIPWAC-measured $\mathrm{CO}_{2}$ line shapes and as expected during this aphelion season.

Approximate position of Figure 2

HIPWAC and SPICAM column abundances retrieved 21-24 February 2008 are displayed over an MGS MOLA topographical image (Smith et al. 2001) in Fig. 3a, with observational details given in Table 2. On Feb. 23, 2008, simultaneous measurements with HIPWAC (A) and SPICAM (orbit 5322) were made over the region northeast of the Tharsis Montes. Ozone abundances retrieved by the two instruments are in very good agreement with each other (Fig. 3b) in this instance where the atmosphere was simultaneously sampled over the same topography at the same Mars local time. The HIPWAC retrieval made at $15^{\circ} \mathrm{N}$ ( $\mathrm{B}$, subsolar point) two hours after the MEX pass, two hours earlier in local time, and at essentially the same pressure as the corresponding SPICAM observation also compares favorably (Fig. 3b).

Approximate position of Figure 3 and Table 2

On Feb. 21, 2008, the beginning of the campaign, a HIPWAC observation 
(Fig 3a, C) was not possible until 1.5 hours after a MEX pass (orbit 5315). The HIPWAC beam covered an altitude region with atmospheric pressure on average 1.5 mbar lower than the area over flown by MEX to the east. The ozone abundance retrieved from HIPWAC (Fig. 3c) was comparable to the SPICAM retrieval. A simple scaling of the HIPWAC column abundance to a GCM-predicted pressure where the SPICAM measurement was made offsets the abundance slightly upward, and the HIPWAC and SPICAM measurements are consistent within their respective uncertainties. However, $\mathrm{O}_{2}\left({ }^{ } \Delta\right)$ dayglow measurements by Novak et al. [2002] and Krasnopolsky [2003, 2007] which indirectly probe ozone above $\sim 20 \mathrm{~km}$ show a shift of peak intensity from high to low latitudes over the course of northern spring toward aphelion. If there is significant contribution to the spectrum from ozone above $20 \mathrm{~km}$, the dependence on topography would be weak and scaling would not be required.

Although not strictly simultaneous, the remaining observations of ozone performed with HIPWAC and SPICAM during the February 2008 campaign show a consistent quantitative behavior with latitude (Fig $3 a$ ). Points $\mathrm{D}$ and $\mathrm{F}$ were measured by HIPWAC a day after the SPICAM measurements along MEX orbit 5315 and points G and $\mathrm{H}$ were measured three days later. The retrievals compare very well, showing low ozone $(<3 \mu \mathrm{m}-\mathrm{atm})$ at low latitudes and a quantitatively consistent increase in ozone abundance at $60^{\circ} \mathrm{N}(8 \mu \mathrm{m}$-atm and increasing $)$.

There is variation among the high southern latitude measurements. At $60^{\circ} \mathrm{S}$, the HIPWAC measurement at $J$ is significantly lower than the measurements a day later at I and at the southern ends of MEX orbits 5325 and 5327. The $\mathrm{J}$ and I measurements were made a day apart and over similar nearby topography. For that reason, day-to-day 
variability due to south polar dynamics may better explain the different abundances. In the case of MEX orbit 5325 , it is likely that underlying topography plays a role in the high ozone abundance measured by SPICAM relative to the other high southern latitude measurements. Orbit 5325 skirted the eastern edge of Argyre Planitia, and the photochemical model of Lefévre et al. [2008] predicts increased (factor of -3) ozone abundance over and just to the east of Argyre relative to the plains over which HIPWAC measurements were made to the west. This is also supported by the lower abundance at the same latitude measured during orbit 5327 over a different region, and by past SPICAM measurements [Perrier et al. 2006]. The combined measurements provide observational support to model predictions and illustrate the important influence of topography on dynamics and related chemistry, and on the resulting variability of ozone abundance with longitude as well as with latitude.

The HIPWAC retrieval at $40^{\circ} \mathrm{N}$ (Fig. $3 a$, E) is significantly larger than the SPICAM retrievals along orbit 5315 made a day earlier. The measurement was made over the Alba Patera region, and the higher altitude would be expected to result in lower column abundance if topography was the only factor. A pointing uncertainty larger than $\sim 5^{\circ}$ on Mars is not expected for the HIPWAC measurement, and to point to higher latitudes requires significant offset in both telescope axes (Fig. $2 a$ ) in order to avoid pointing off of Mars altogether, which is unlikely. The dynamic north polar region is a more likely explanation for the difference. The other SPICAM measurements vary significantly between $40^{\circ} \mathrm{N}$ and $60^{\circ} \mathrm{N}$ although the topography does not vary greatly except for Alba Patera. The high ozone abundance retrieved by HIPWAC may be due to the close proximity of the north polar vortex and may in fact trace the large day-to-day 
variability at the edge of the vortex.

Approximate position of Figure 4

Observations were made by HIPWAC in October 2007 at $\mathrm{L}_{s}=336^{\circ}$ (late northern winter) during SPICAM operation. Retrieved ozone abundances and upper limits are shown in Fig. 4, along with the observing geometry where the dotted line represents the path of SPICAM nadir observations beyond the limb of Mars as visible from Earth. Strictly simultaneous observations were not possible, but retrievals made with a maximum time difference of 2-3 days at the same latitude can be compared.

Approximate position of Figure 5

Nadir observations by SPICAM in October 2007 took place at high southern latitudes, at a Mars local time of $-7: 00$. Retrieved abundances, along with those from HIPWAC at local times of 10:30-11:30, are displayed in Fig. 5. SPICAM measured very little or no ozone, as would be expected during this late southem summer period when the combination of season and proximity to perihelion creates conditions in the south favoring higher water vapor abundance, and therefore lower ozone abundance. Upper limits of only $0.5 \mu \mathrm{m}$-atm retrieved by HIPWAC at $40^{\circ} \mathrm{S}$ are consistent with the lack of ozone observed by SPICAM at the same position 2-3 days later and at other positions during the week of measurements (except for increased ozone measured over Hellas). Ozone abundance measured by HIPWAC increases toward high northern (winter) latitudes to $\sim 3$ um-atm. Since the HIPWAC and SPICAM measurements do not differ by 
a large amount in local time ( -4 hours), the consistency at $40^{\circ} \mathrm{S}$ can link the two data sets, allowing them to be combined in the testing of photochemical models and demonstrating the complementary nature of the two sets of observations.

Approximate position of Figure 6

Observations by HIPWAC in February 2006 at $L_{S}=12^{\circ}$ (early northern spring) were the first made during the MEX mission, and the observing geometry is given in Fig. 6a. These HIPWAC measurements did not target a SPICAM comparison at the time and were limited by weather. Due to the smaller size of Mars, the HIPWAC bean covered $\sim 18^{\circ}$ of latitude centered at $40^{\circ} \mathrm{N}$. Retrievals represent average ozone abundance over the regions measured, and HIPWAC retrieved $1.52 \pm 0.29$ and $0.87 \pm 0.59 \mu \mathrm{m}$-atm on 14 and 15 Feb. 2006, respectively, at local Martian noon. The HIPWAC retrievals and those made by SPICAM during Feb. 12-18 at $\sim 8: 00$ Mars local time are displayed in Fig. $6 b$.

Previous observations by SPICAM [Perrier et al. 2006] revealed large day-to-day variability of ozone abundance in this high latitude region. Such variability was also predicted by GCM simulations of Lefevvre et al. [2004] and is evident in the SPICAM measurements displayed in Fig $6 b$. This complicates the comparison because the HIPWAC and SPICAM observations do not strictly coincide spatially and temporally. The MEX orbit 2689 on 14 Feb. took place during the time between the two HIPWAC measurements at similar latitude although at a different longitude on Mars. Orbit 2683 on $13 \mathrm{Feb}$. coincides spatially with the HIPWAC measurements but not temporally. Orbit 2697 took place two days after the HIPWAC measurement and covers the entire 
latitude region sampled, although at a different longitude. Retrievals in the region around $40^{\circ} \mathrm{N}$ appear consistent when considering the rapid decrease in ozone abundance observed by SPICAM from the polar region down through the range of latitudes probed by HIPWAC. This also indicates minimal variation in ozone abundance over the four hours of Mars local time between SPICAM and HIPWAC measurements.

\section{COMPARISON TO PREVIOUS MEASUREMENTS}

Infrared heterodyne measurements were made 14-16 February 1993 during midspring, $L_{S}=40^{\circ}$, by HIPWAC's predecessor, NASA/GSFC's Infrared Heterodyne Spectrometer (IRIIS). Operating at the Coude focus of the NASA/IRTF rather than at the Cassegrain, IRHS was otherwise identical to HIPWAC in terms of fundamental design and operation. The 1993 measurements made by IRIIS took place at essentially the same Martian season as the February 2008 HIPWAC and SPICAM observations, and all three data sets are displayed in Fig. $3 a$. The high latitude IRHS retrievals are generally consistent with both HIPWAC and SPICAM, including a $40^{\circ} \mathrm{S}$ measurement showing increased ozone on the eastem edge of Argyre Planitia, further supporting the earlier discussion of the spatial distribution of ozone in this region. The striking difference is in the low latitude retrievals. Column abundances measured by IRHS in Mars Year (MY) 21 are consistently $\sim 2-4$ times higher than those retrieved by HIPWAC and SPICAM in MY29, eight Martian years later during the same northern mid-spring season. This is significant, as photochemical models have generally been checked against combined ground- and space-based measurements made over many Martian years. Although ozone exhibits large spatial, diurnal, and seasonal variability, year-to-year variability is not as 
well-studied.

Previous comparisons of retrievals from SPICAM and from HIPWAC and IRHS as well as Hubble Space Telescope (HST) UV measurements [Clancy et al. 1996, 1999] were only possible using data sets taken during the same Martian season in different years. A comparison of archival IR heterodyne measurements to HST UV measurements showed generally consistent retrievals for contemporaneous observations as well as for those at similar $L_{S}$ within a few years of each other [Fast et al. 2006a]. Measurements by Clancy et al. [1999] using HST at $\mathrm{L}_{\mathrm{S}}=10^{\circ}$ in 1996 were very consistent with those from SPICAM during the $L_{S}=0^{\circ}-30^{\circ}$ season in a later Martian year. IR heterodyne measurements by IRHS and HIPWAC at $\mathrm{LS}_{\mathrm{S}}=202^{\circ}$ and $208^{\circ}$ also yielded results consistent with those from SPICAM during the $L_{S}=180^{\circ}-210^{\circ}$ season, again in a later Martian year. However, during $L_{5}=60^{\circ}-90^{\circ}$ (late northern spring) both HST and IRHS yielded approximately two to five times more ozone in the $1990^{\circ} \mathrm{s}$ than was observed by SPICAM at similar seasons, but one decade later. This was attributed to possible interannual variability by Perrier et al. [2006], who did not see interannual variability in the data from the two consecutive Martian springs that SPICAM had measured. Results presented here for $\mathrm{L}_{\mathrm{S}}=35^{\circ}$ (northern mid-spring) in 2008 (MY29) support the quantitative comparison of IR heterodyne and UV measurements of ozone. The addition of the 1993 IRHS retrievals from 1993 (MY21) points to variability during aphelion that may only be evident on timescales longer than a few Martian years.

Possible interannual or inter-decadal variability of ozone points to variability in the physical parameters that ozone traces. Ozone is destroyed by the odd hydrogen products of water photolysis and its abundance has been observed to be anticorrelated 
with observed and modeled abundances of water vapor [e.g., Lane et al. 1973, Fast et al. 2006a. Perrier et al. 2006]. Although we have been able to link observed ozone abundances quantitatively between decades through the use of consistent instrumentation and techniques, relating observed water vapor abundance is not as straightforward. Water vapor on Mars was measured from the ground during the period between monitoring from Mars orbit by Viking [e.g., Farmer et al. 1997] and Mars Global Surveyor [e.g., Smith 2002]. Observations were made by Sprague et al. [1996] in March of 1993 at $\mathrm{L}_{\$}=50^{\circ}$, soon after the IRHS measurements of ozone. Their retrieved water vapor abundances were higher than those retrieved at the same season in later years by TES, which did not see significant year-to-year variability over the course of the mission. However, water vapor abundances measured with MRO-CRISM [Smith et al. 2009] during the Feb. 2008 HIPWAC and SPICAM ozone measurements were lower than those seen by MGS-TES during previous northern mid-springs. Variability in water vapor abundance between 1993 and 2008 could explain the different retrieved ozone abundances. However, higher water vapor abundance in 1993 and lower abundance in 2008 is the opposite of what would be expected in this case of increased ozone abundance at low latitudes in 1993 over that which was observed in 2008.

Another physical parameter that affects ozone is the abundance of water ice cloud particles. Water ice clouds are present at low latitudes during aphelion seasons and can provide a heterogeneous sink for the odd hydrogen species that destroy ozone. Recent work by Lefèvre et al. [2008] has shown that the application of laboratory-measured loss rates of odd hydrogen species onto water ice brings their photochemical model into closer agreement with aphelion measurements of ozone. Model-predicted and observed ozone 
abundances at low latitudes increase rapidly over the $\mathrm{Ls}=30^{\circ}-60^{\circ}$ interval. The increased low-latitude ozone in 1993 may reflect the $5^{\circ}$ difference in $L_{S}$ between the 2008 and 1993 observations or actual variation in the onset of cloud activity. Although interannual variation in aphelion clouds was not evident to MGS-TES over the duration of the mission [Smith et al. 2004], it could be that the aphelion IRHS and HST observations may have probed somewhat different conditions in the $1990^{\circ} \mathrm{s}$ than those measured by HIPWAC and SPICAM a decade later. Members of the Association of Lunar and Planetary Observers who monitored Mars in 1993 noted both early onset of cloud activity [Parker and Berry 1993, Troiani et al. 1995] and seasonally normal cloud activity [McKim 1995]. Variations in cloud activity may explain the low latitude discrepancy between the sets of observations at $\mathrm{L}_{\mathrm{S}}=35^{\circ}-40^{\circ}$ presented here and needs to be further investigated.

Although it would not be expected for the lower atmosphere to be strongly affected by solar activity variation due to the solar cycle, it can be noted that the 1993 IRHS measurements were made after the peak of solar cycle 22, while the 2008 HIPWAC and SPICAM measurements were made during the minimum after cycle 23 , with monthly mean sunspot numbers of 91 and 2 , respectively'.

\section{CONCLUSIONS}

We have presented the first comparison of ozone measurements made by HIPWAC and SPICAM since the start of the Mars Express mission. Simultaneous

\footnotetext{
'SIDC-team, World Data Center for the Sunspot Index, Royal Observatory of Belgium, Monthly Report on the International Sunspot Number, online catalogue of the sunspot index: http:/www.sidc.be/sunspot-data/, 1993 \& 2008.
} 
measurements and measurements made close in time by these IR and UV instruments are largely consistent, supporting direct comparison as well as combination for testing GCMs and photochemical models. Outliers can be explained by differences in topography and by dynamics. In 2008, the high ozone abundance over Alba Patera from HIPWAC relative to SPICAM may trace the large day-to-day variability at the edge of the north polar vortex, as also evidenced by SPICAM measurements at other longitudes. Increased ozone at Argyre Planitia was seen in these data sets, as well as at the same season of northern spring in 1993 by HIPWAC's predecessor, IRHS. These observational results constrain models predicting the influence of topography on dynamics and related chemistry. In 2007 , the consistency of ozone retrievals in an overlap region at $40^{\circ} \mathrm{S}$ permits the synergistic combination of south polar data by SPICAM and northern hemisphere data from HIPWAC, allowing them to be used together to probe of Martian photochemistry in late northern winter.

The consistency of measurements from HIPWAC and SPICAM permit a quantitative comparison to older IR heterodyne measurements by IRHS. Measurements in 2008 by HIPWAC and SPICAM compare well to a seasonally similar data set from IRHS in 1993 except at low latitudes where 1993 abundance were 2-4 times higher, and where clouds form during northern spring. The differences in these aphelion measurements imply long-timescale variability of ozone and provide constraints on models of Martian atmospheric chemistry that involve heterogeneous processes on cloud particles.

Future opportunities to observe Mars using HIPW AC will occur in late 2009 and early 2010 during Martian spring, MY30. Observations coordinated with SPICAM that 
target additional simultaneous measurements are important for providing further evidence for results presented here and for constraining photochemical models. Simultaneous and contemporaneous measurements thus far indicate general agreement between IR and UV results, and observations at different aphelion years suggest significant temporal variability of ozone on Mars. Future HIPWAC observations can target the diurnal behavior of ozone and complement SPICAM observations through measurements at multiple local times. Measurement of the vertical distribution of ozone can probe water vapor distribution and photochemical processes with altitude. True line shapes measured by HIPWAC, nadir and limb measurements by SPICAM, and $\mathrm{O}_{2}\left({ }^{1} \Delta\right)$ dayglow emission probing high altitudes [e.g. Novak et al. 2002, Krasnopolsky 2003, 2007] can be combined to investigate the vertical distribution of ozone and future coordinated observations can target such a goal.

\section{ACKNOWLEDGEMENTS}

The authors thank Dr. Alan Tokunaga and the staff of the NASA Infrared Telescope Facility for their support of HIPWAC observations of Mars. This work was supported by the NASA Planetary Astronomy Program. 


\section{REFERENCES}

Bertaux, J.-L., Fonteyn, D., Korablev, O., Chassefière, E., Dimarellis, E., Dubois, J.P., Hauchecone, A., Cabane, M., Rannou, P., Levasseur-Regourd, A.C., Cernogora, G., Quemerais, E., Hermans, C., Kockarts, G., Lippens, C., De Maziere, M., Moreau, D., Muller, C., Neefs, B., Simon, P.C., Forget, F., Hourdin, F., Talagrand, O., Moroz, V.I., Rodin, A., Sandel, B., Stern, A., 2000. The study of the martian atmosphere from top to bottom with SPICAM light on Mars Express. Planet. Space Sci. 48, 1303-1320.

Blamont, J. E., and E. Chassefiére 1993. First detection of ozone in the middle atmosphere of Mars from solar occultation measurements. Icarus 104, 324 336.

Clancy, R. T., M. J. Wolff, P. B. James, E. Smith, Y. N. Billawala, S. W. Lee, and M. Callan 1996. Mars ozone measurements near the 1995 aphelion: Hubble Space Telescope ultraviolet spectroscopy with the Faint Object Spectrograph. J. Geophys, Res. $101,12,777-12,783$.

Clancy, R. T., M. J. Wolff, and P. B. James 1999. Minimal aerosol loading and global increases in atmospheric ozone during the 1996-1997 Martian northern spring season. lcarus $138,49-63$

Edwards, D. P. 1992. GENLN2: A general line-by-line atmospheric transmittance and radiance model: Version 3.0 description and users guide, Rep. NCAR/TN-367+STR, Natl. Cent. for Atmos. Res., Boulder, Colo.

Espenak, F., M. J. Mumma, and T. Kostiuk 1991. Ground-based infrared measurements of the global distribution of ozone in the atmosphere of Mars. Icarus 92, 252-262.

Farmer, C. B., D. W. Davies, A. L. Holland, D. D. Laporte, P. E. Doms 1977. Mars Water vapor observations from the Viking orbiters, JGR 82, 4225 4248, doi: $10.1029 / \mathrm{JS} 082 \mathrm{i} 028 \mathrm{p} 04225$.

Fast, K. E. Mars ozone abundances from infrared heterodyne spectra and their application to study of the stability of the Martian atmosphere. Ph.D. dissertation, University of Maryland, 2005.

Fast, K. E. T. Kostiuk, F. Espenak, J. Annen, D. Buhl, T. Hewagama, M. F. A'Hearn, D. Zipoy. T. A. Livengood, G. Sonnabend and F. Schmülling 2006a. Ozone abundance on Mars from infrared heterodyne spectra I: Acquisition, retrieval, and anticorrelation with water vapor. Icarus, $I 81,419-431$, doi: $10.1016 /$ j.icarus.2005.12.001.

Fast, K. E., T. Kostiuk, T. Hewagama, M. F. A'Hearn, T. Livengood, S. Lebonnois and F. Lefèvre 2006b. Ozone abundance on Mars from infrared heterodyne spectra II: Validating photochemical models. Icarts, $183, \quad 396402$, doi:10.1016/j.icarus.2006.03.012.

Hewagama, T., J. Goldstein, T. Livengood, D. Buhl, F. Espenak, K. Fast, Th. Kostiuk, and F. Schmülling 2008. Beam integrated high-resolution infrared spectra: Accurate modeling of thermal emission from extended clear atmospheres. JOSRT 109, 10811097 doi:10.1016/j.jqsrt.2007.12.022.

Kostiuk, T. 1994. Physics and chemistry of upper atmospheres of planets from infrared observations. Infrared Phys. Technol. 35, 243-266.

Krasnopolsky, V. A. 2003. Mapping of Mars $\mathrm{O}_{2} 1.27 \mu \mathrm{m}$ dayglow at four seasonal 
points. Icarus $165,315-325$.

Krasnopolsky, V. A., 2006. Photochemistry of the Martian atmosphere: Seasonal, latitudinal, and diurnal variations, Icarus, doi:10.1016/j.icarus.2006.06.003.

Krasnopolsky, V. A., 2007. Long-term spectroscopic observations of Mars using IRTF/CSHELL: Mapping of O2 dayglow, CO, and search for CH4, Icarus 190, 93-102, doi: $10.1016 /$ j.icarus.2007.02.014.

Krasnopolsky, V. A., A. A. Krysko, V. N. Rogachev 1975. Measurement of ozone in a planetary atmosphere by space probe Mars-5. Cos. Res., 13, p. 31-34.

Lane, A. L., C. A. Barth, C. W. Hord, and A. I. Stewart 1973. Mariner 9 ultraviolet spectrometer experiment: Observations of ozone on Mars. Icarus 18, 102-108.

Lebonnois, S., E. Quémerais, F. Montmessin, F. Lefèvre, S. Perrier, J.-L. Bertaux and F. Forget 2006. Vertical distribtuion of ozone on Mars as measured by SPICAM/Mars Express using stellar occultations. J. Geophys, Res., 111, E09S05, doi: $10.1029 / 2005 J E 002643$.

Lefèvre, F., Lebonnois, S., Montmessin, F., Forget, F., 2004. Three-dimensional modeling of ozone on Mars. J. Geophys. Res. 109, doi:10.1029/ 2004JE002268. E07004.

Lefèvre, F., J.-L. Bertaux, R. T. Clancy, T. Encrenaz, K. Fast, F. Forget, S. Lebonnois, F. Montmessin and S. Perrier 2008. Heterogeneous chemistry in the atmosphere of Mars, Nature 454, 971-975, doi:10.1038/nature07116.

McKim, R. J. 1995. The opposition of Mars, 1993. J. Brit. Astron. Assoc, 105, 117.

Malin, M. C., J. F. Bell III, W. Calvin, R. T. Clancy, R. M. Haberle, P. B. James, S. W. Lee, P. C. Thomas and M. A. Caplinger 2001. Mars Color Imager (MARCI) on the Mars Climate Orbiter. JGR 106, No. E8, 17,651-17,672.

Novak, R. E., M. J. Mumma, M. A. DiSanti and N. Dello Russo 2002. Mapping of ozone and water in the atmosphere of Mars near the 1997 aphelion. Icarus 158, 14-23.

Parker, D. C. and R. Berry 1993. Clear skies on Mars. Astronomy, 21, 72-77.

Perrier, S., J.-L. Bertaux, F. Lefèvre, S. Lebonnois, O. Korablev, A. Fedorova and F. Montmessin 2006. Global distribution of total ozone on Mars from SPICAM/MEX UB measurements. J. Geophys. Res., 111, E09S06, doi:10.1029/2006JE002681.

Schmude, R. W., Jr. and D. Bruton 1994. Observations of Mars in 1992-93. J. Roy. Astron. Soc. Canada, 88, 69.

Smith, D. E., M. T. Zuber, H. V. Frey, J. B. Garvin, J. W. Head, D. O. Muhleman, G. H. Pettengill, R. J. Phillips, S. C. Solomon, H. J. Zwally, W. B. Banerdt, T. C. Duxbury, M. P. Golombek, F. G. Lemoine, G. A. Neumann, D. D. Rowlands, O. Aharonson, P. G. Ford, A. B. Ivanov, P. J. McGovern, J. B. Abshire, R. S. Afzal and X. Sun 2001. Mars Orbiter Laser Altimeter (MOLA): Experiment summary after the first year of global mapping of Mars, J. Geophys. Res., 106, 23,689-23,722.

Smith, M.D., 2002. The Annual Cycle of Water Vapor on Mars as Observed by the Thermal Emission Spectrometer. J. Geophys. Res., 107, doi: 10.1029/2001JE001522. 
Smith, M. D. 2004. Interannual variability in TES atmospheric observations of Mars during 1999 2003. lcarus 167, 148" 165.

Smith, M. D., M. J. Wolff, R. T. Clancy and S. L. Murchie 2009. CRISM observations of water vapor and carbon monoxide. JGR, in press.

Sprague, A. L., D. M. Hunten, R. E. Hill, B. Rizk, and W. K. Wells 1996. Martian water vapor, 1988-1995. J. Geophys. Res I01, 23,229-23,241.

Troiani, D. M., J. D. Beish, D. C. Parker, C. E. Hernandez 1995. J. Assoc. Lunar \& Planet. Obs., 38,97 . 


\section{FIGURE CAPTIONS}

Figure 1: HIPWAC spectrum (histogram) taken on 22 February 2008 at $60^{\circ} \mathrm{N}$ and $11: 30$ local time on Mars, along with model spectrum (solid). Telluric contribution has been modeled and removed, and the original $1 \mathrm{MHz}$-resolution Mars-only spectrum has been smoothed to $10 \mathrm{MHz}$ for clarity and shown as single-sideband. Present in the spectrum are an ozone absorption feature, a $\mathrm{CO}_{2}$ absorption feature used to measure atmospheric temperature in the region of ozone contribution, and a high-altitude non-LTE emission feature useful for other temperature and dynamical applications.

Figure 2: a) Observing geometry for Mars during Feb. 2008 HIPWAC observations at $\mathrm{L}_{\mathrm{S}}=35^{\circ}$ (northern mid-spring). The path of SPICAM nadir observations is shown as a solid line along the right limb (asterisk=subsolar point). b) Total ozone column abundances and upper limits measured by HIPWAC 21-24 Feb. 2008 as a function of latitude.

Figure 3: a) HIPWAC and SPICAM ozone retrievals from 21-24 February 2008 $\left(\mathrm{L}_{\mathrm{S}}=35^{\circ}\right)$ displayed over MGS MOLA topographical image. Individual colored regions show HIPWAC observational coverage and retrieved average ozone column. Colored tracks show ozone column abundances retrieved by SPICAM during Mars Express orbital passes. Key to labeling is given in Table 2. Hatched regions show ozone retrievals made at a similar season $\left(\mathrm{L}_{\mathrm{S}}=40^{\circ}\right)$ in February 1993 by HIPWAC's predecessor, IRHS. All retrievals are consistent at high latitudes, but the 1993 low latitude retrievals are significantly higher than the 2008 measurements. Variations in cloud activity may explain the low latitude discrepancy, as heterogeneous chemistry 
involving clouds can lead to increased ozone abundance. b) Ozone column abundances from HIPWAC (red squares) and SPICAM (blue diamonds). On Feb. 23, HIPWAC's integration at $20^{\circ} \mathrm{N}$ (A) was simultaneous with the SPICAM, and both retrievals are very consistent. A HIPWAC observation at $15^{\circ} \mathrm{N}$ (subsolar latitude, B) made two hours after SPICAM, two hours earlier in local time, and at essentially the same pressure is also consistent with SPICAM. c) On Feb. 21, the HIPWAC observation (C) was made less than two hours after the SPICAM observations. The HIPWAC column abundance scaled to the pressure of the SPICAM observation (purple triangle) is consistent with SPICAM retrievals within the uncertainties of both.

Figure 4: a) Observing geometry for Mars during Oct. 2007 HIPWAC observations at $\mathrm{L}_{\mathrm{S}}=336^{\circ}$ (late northern winter). The path of SPICAM nadir observations, limited to the southern hemisphere, was not visible from. Earth, as shown by the dashed line representing the path on the other side of the visible limb (asterisk=subsolar point). b) Total ozone column abundances and upper limits measured by HIPWAC 24-26 Oct. 2007.

Figure 5: October 2007 HIPWAC and SPICAM ozone retrievals displayed over MGS MOLA topographical image. Individual colored regions show HIPWAC observational coverage and retrieved average ozone column (24-26 Oct. 2007). Colored tracks show ozone column abundances retrieved by SPICAM during Mars Express orbital passes (2228 Oct. 2007). Abundances retrieved by both instruments were very low in the southern hemisphere and show a slight increase at Hellas Planitia.

Figure 6: a) Observing geometry for Mars during Feb. 2006 HIPWAC observations at 
$L_{S}=12^{\circ}$ (early northern spring) which were targeted for a purpose other than direct comparison. The $\sim 8: 00$ path of SPICAM nadir observations is shown as a solid line (asterisk=subsolar point). b) HIPWAC and SPICAM ozone retrievals displayed over MGS MOLA topographical image. Individual colored regions show HIPWAC observational coverage and retrieved average ozone column abundance (14-15 Feb. 2006). Colored tracks show ozone column abundances retrieved by SPICAM during Mars Express orbital passes (12-18 Feb. 2006). 

Table 1

\begin{tabular}{|c|c|c|c|c|c|}
\hline $\begin{array}{c}\text { UT } \\
\text { Dates }\end{array}$ & $\mathrm{L}_{\mathrm{s}}$ & $\begin{array}{l}\text { Northern } \\
\text { Martian } \\
\text { Season } \\
\end{array}$ & $\begin{array}{c}\text { Mars } \\
\text { Diameter }\end{array}$ & $\begin{array}{c}\text { IR Heterodyne } \\
\mathrm{CO}_{2} \text { Laser } \\
\text { Local Oscillator }\end{array}$ & $\begin{array}{c}\text { Instrument } \\
\text { (Mars Local Time) }\end{array}$ \\
\hline $\begin{array}{c}2008 \\
\text { February } \\
21-24\end{array}$ & $35^{\circ}$ & $\begin{array}{l}\text { Mid } \\
\text { Spring }\end{array}$ & $9.7^{\prime \prime}$ & $\begin{array}{c}6269 \mathrm{PlO} \\
1055.6251 \mathrm{~cm}^{-1} \\
9.47 \mu \mathrm{m}\end{array}$ & $\begin{array}{l}\text { HIPWAC }(12: 40-14: 00) \\
\text { MEX-SPICAM } \\
\text { MEX }(14: 30)\end{array}$ \\
\hline $\begin{array}{c}2007 \\
\text { October } \\
24-26\end{array}$ & $336^{\circ}$ & $\begin{array}{l}\text { Late } \\
\text { Winter }\end{array}$ & $11.5^{\circ}$ & $\begin{array}{c}6269 \mathrm{P3} 6 \\
1031.4774 \mathrm{~cm}^{1} \\
9.69 \mu \mathrm{m}\end{array}$ & $\begin{array}{l}\text { HIPWAC }(10: 30-11: 30) \\
\text { MEX-SPICAM }{ }^{3}(07: 00)\end{array}$ \\
\hline $\begin{array}{c}2006 \\
\text { February } \\
14-15\end{array}$ & $12^{\circ}$ & $\begin{array}{l}\text { Early } \\
\text { Spring }\end{array}$ & $7.9^{\prime \prime}$ & $\begin{array}{c}6269 \mathrm{Pl0} \\
1055.6251 \mathrm{~cm}^{-1} \\
9.47 \mu \mathrm{m}\end{array}$ & $\begin{array}{c}\text { HIPWAC }(12: 00) \\
\text { MEX } \text { SPICAM }^{3}(08: 00)\end{array}$ \\
\hline $\begin{array}{c}1993 \\
\text { February } \\
14-16\end{array}$ & $40^{\circ}$ & $\begin{array}{l}\text { Mid } \\
\text { Spring }\end{array}$ & $11.6^{\prime \prime}$ & $\begin{array}{c}6269 \mathrm{P32} \\
1035.4736 \mathrm{~cm}^{-1} \\
9.66 \mu \mathrm{m}\end{array}$ & IRHS $^{2}(10: 30-14: 00)$ \\
\hline
\end{tabular}

NASA/GSFC Heterodyne Instrument for Planetary Wind and Composition

${ }^{2}$ NASA/GSFC Infrared Heterodyne Spectrometer

${ }^{3}$ Mars Express Spectroscopy for the Investigation of the Characteristics of the Atmosphere of Mars

Table 2: Coordinated HIPWAC and Mars Express SPICAM measurements in February of 2008. Bold indicates observations made simultaneously or within two hours of each other.

\begin{tabular}{ccc}
\hline UT Date & $\begin{array}{c}\text { HIPWAC } \\
\text { Observations } \\
\text { in Fig. } 4\end{array}$ & MEX orbit number \\
\hline $2 / 21 / 08$ & C & $5314,5315,5317$ \\
\hline $2 / 22 / 08$ & D, E, F, K & 5320 \\
\hline $2 / 23 / 08$ & A, B, J & 5322,5324 \\
\hline $2 / 24 / 98$ & G, H, l & 5325,5327 \\
\hline
\end{tabular}


Figure 1

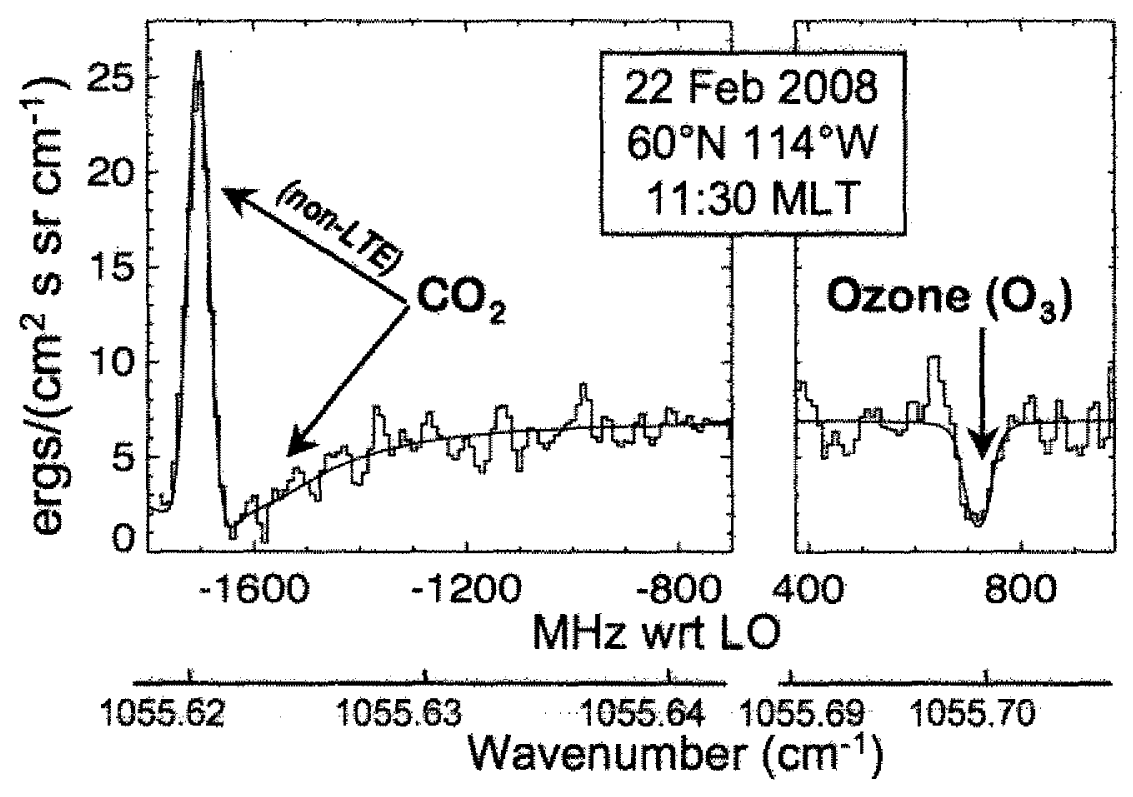

Figure 1: HIPWAC spectrum (histogram) taken on 22 February 2008 at $60^{\circ} \mathrm{N}$ and $11: 30$ local time on Mars, along with model spectrum (solid). Telluric contribution has been modeled and removed, and the original $1 \mathrm{MHz}$-resolution Mars-only spectrum has been smoothed to $10 \mathrm{MHz}$ for clarity and shown as single-sideband. Present in the spectrum are an ozone absorption feature, a $\mathrm{CO}_{2}$ absorption feature used to measure atmospheric temperature in the region of ozone contribution, and a high-altitude non-LTE emission feature useful for other temperature and dynamical applications, 
Figure 2

a)

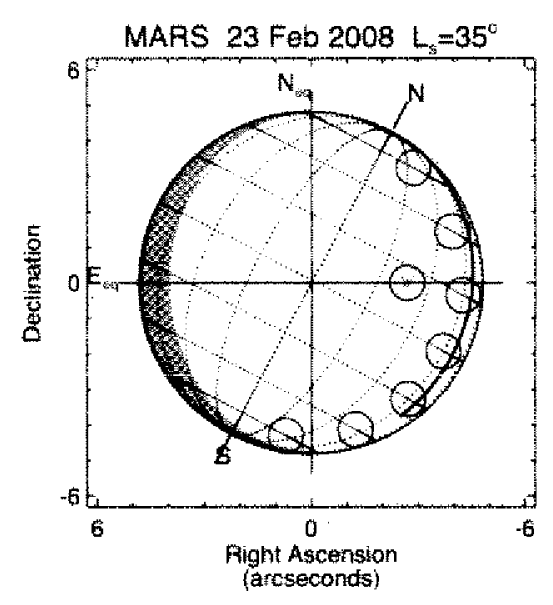

b)

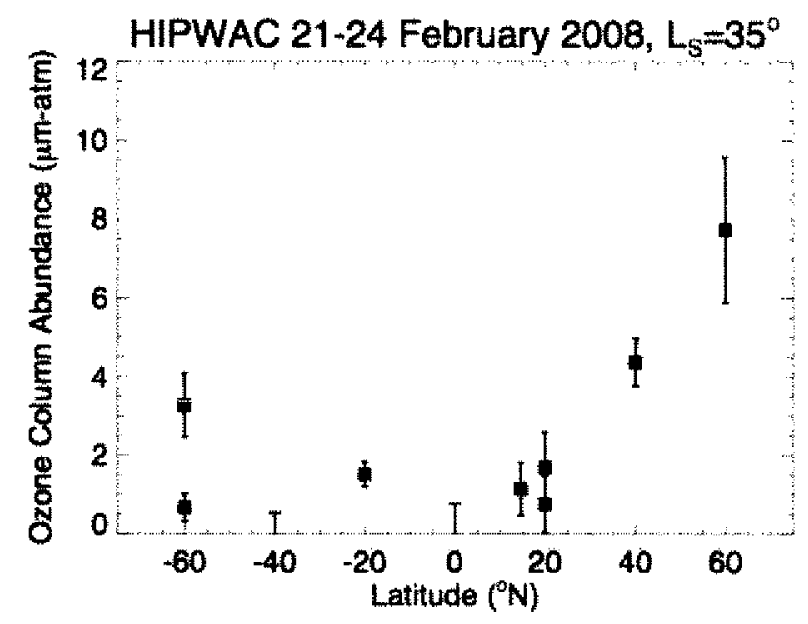

Figure 2: a) Observing geometry for Mars during Feb. 2008 HIPWAC observations at $\mathrm{L}_{\mathrm{S}}=35^{\circ}$ (northern mid-spring). The path of SPICAM nadir observations is shown as a solid line along the right limb (asterisk=subsolar point). b) Total ozone column abundances and upper limits measured by HIPWAC 21-24 Feb. 2008 as a function of latitude. 
Figure 3

a)

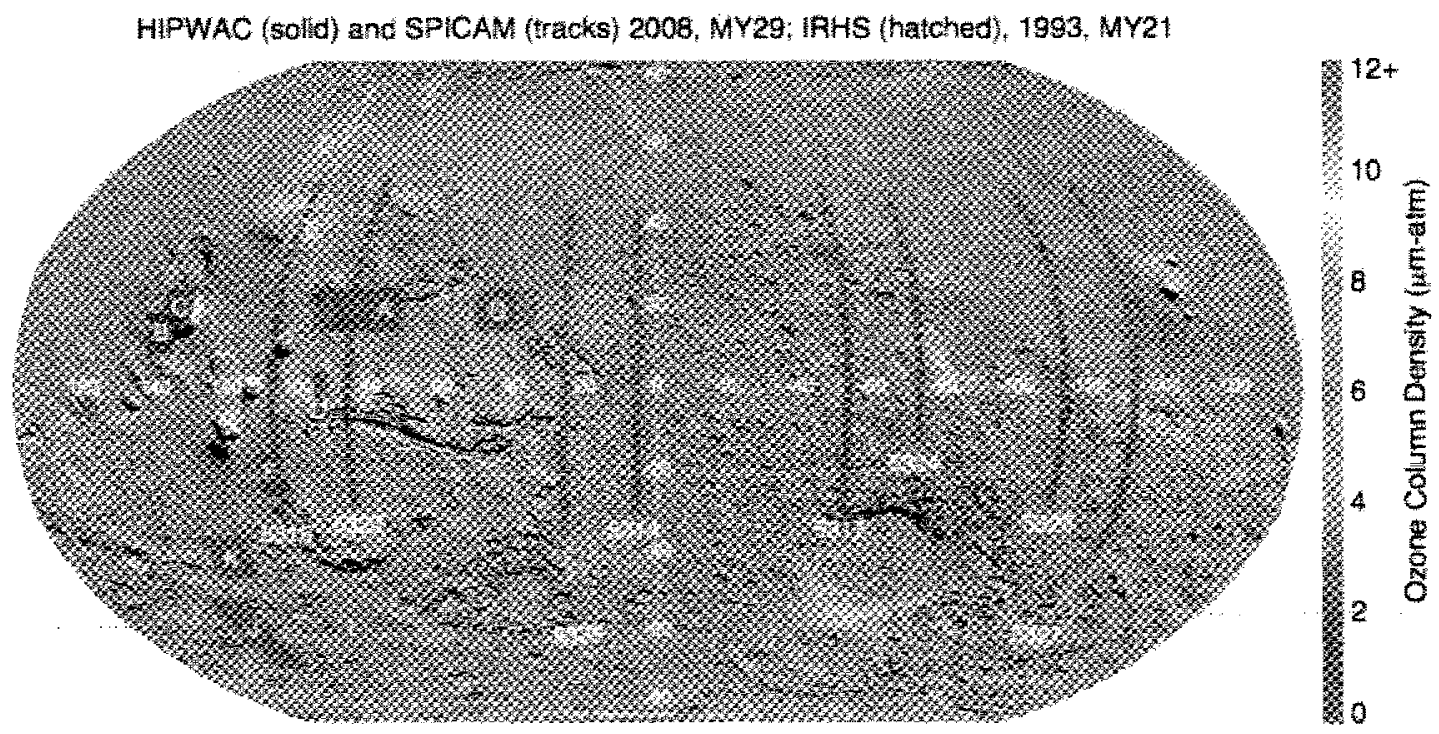

b)

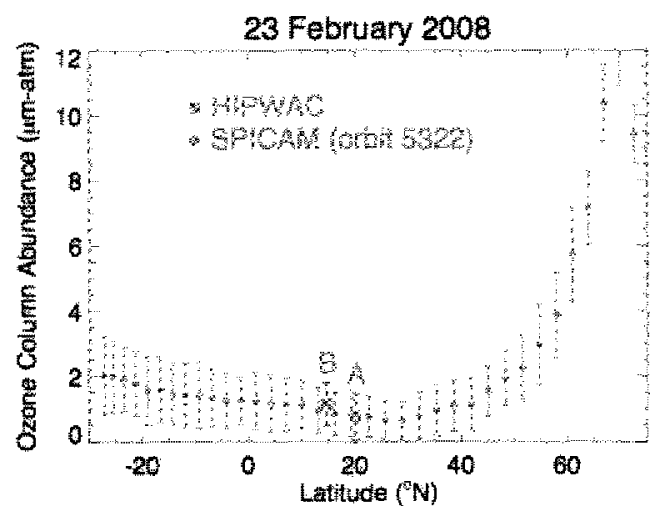

c)

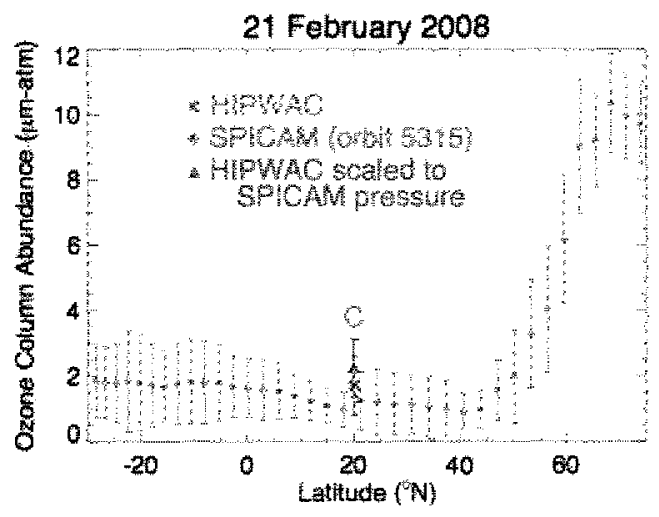

Figure 3: a) HIPWAC and SPICAM ozone retrievals from 21-24 February 2008 $\left(L_{S}=35^{\circ}\right)$ displayed over MGS MOLA topographical image. Individual colored regions show HIPWAC observational coverage and retrieved average ozone column. Colored tracks show ozone column abundances retrieved by SPICAM during Mars Express orbital passes. Key to labeling is given in Table 2. Hatched regions show ozone retrievals made at a similar spring season $\left(\mathrm{L}_{s}=40^{\circ}\right)$ in February 1993 by HIPWAC's predecessor, IRHS. All retrievals are consistent at high latitudes, but the 1993 low latitude retrievals are significantly higher than the 2008 measurements. Variations in 
cloud activity may explain the low latitude discrepancy, as heterogeneous chemistry involving clouds can lead to increased ozone abundance. b) Ozone column abundances from HIPWAC (red squares) and SPICAM (blue diamonds). On Feb. 23, HIPWAC's integration at $20^{\circ} \mathrm{N}(\mathrm{A})$ was simultaneous with the SPICAM, and both retrievals are very consistent. A HIPWAC observation at $15^{\circ} \mathrm{N}$ (subsolar latitude, B) made two hours after SPICAM, two hours earlier in local time, and at essentially the same pressure is also consistent with SPICAM. c) On Feb. 21, the HIPWAC observation (C) was made less than two hours after the SPICAM observations. The HIPWAC column abundance scaled to the pressure of the SPICAM observation (purple triangle) is consistent with SPICAM retrievals within the uncertainties of both. 
Figure 4

a)

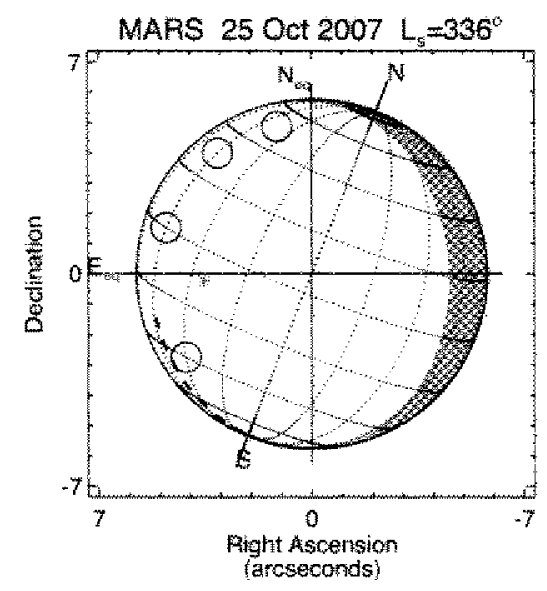

b)

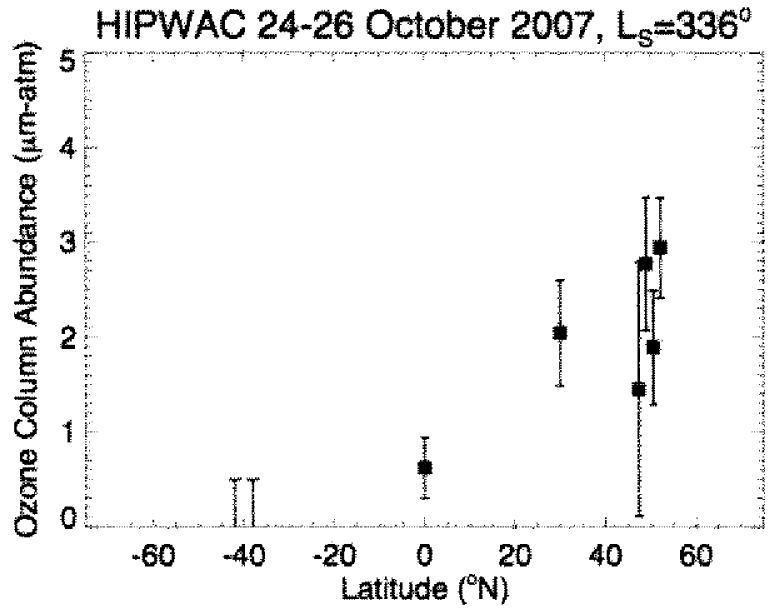

Figure 4: a) Observing geometry for Mars during Oct. 2007 HIPWAC observations at $L_{S}=336^{\circ}$ (late northern winter). The path of SPICAM nadir observations, limited to the southern hemisphere, was not visible from Earth, as shown by the dashed line representing the path on the other side of the visible limb (asterisk=subsolar point). b) Total ozone column abundances and upper limits measured by HIPWAC 24-26 Oct. 2007. 
Figure 5

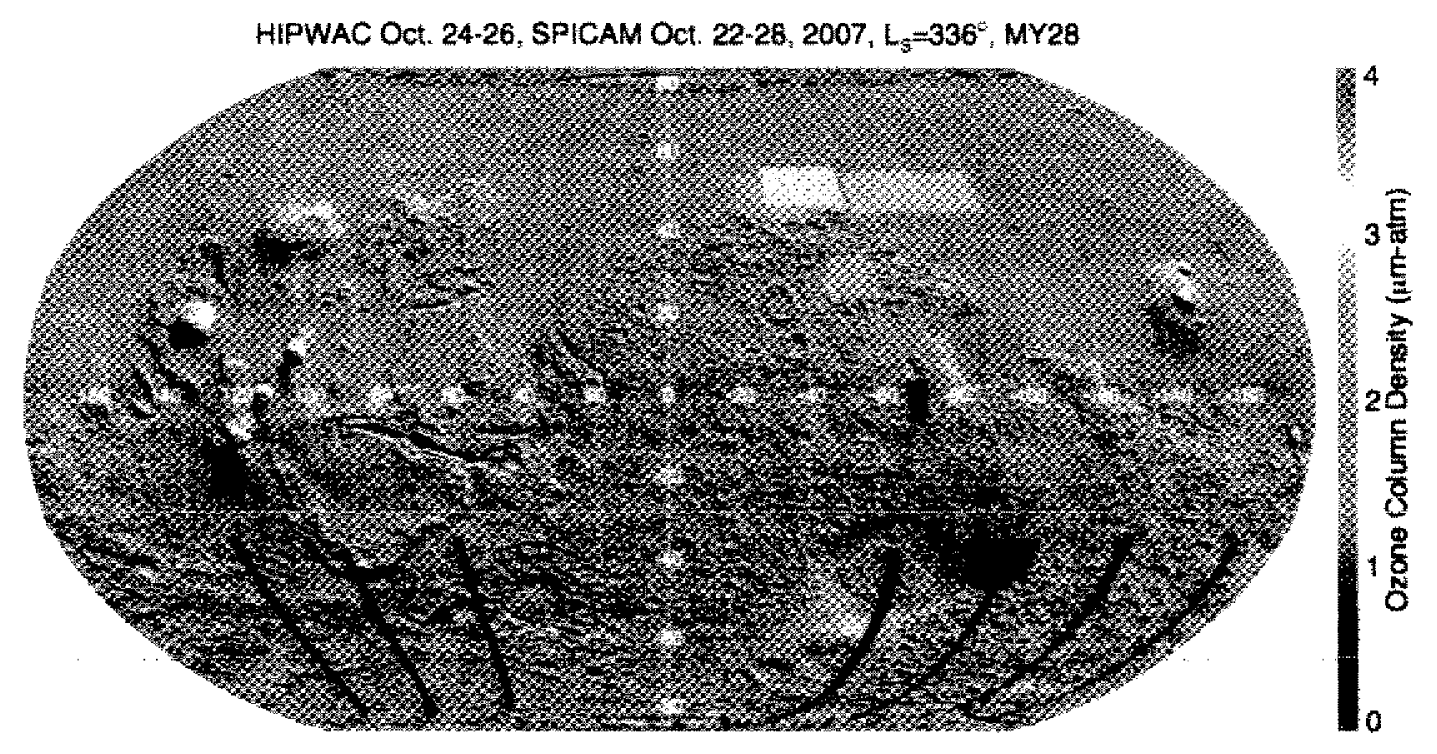

Figure 5: October 2007 HIPWAC and SPICAM ozone retrievals displayed over MGS MOLA topographical image. Individual colored regions show HIPWAC observational coverage and retrieved average ozone column (24-26 Oct. 2007). Colored tracks show ozone column abundances retrieved by SPICAM during Mars Express orbital passes (2228 Oct. 2007). Abundances retrieved by both instruments were very low in the southern hemisphere and show a slight increase at Hellas Planitia. 
Figure 6

a)

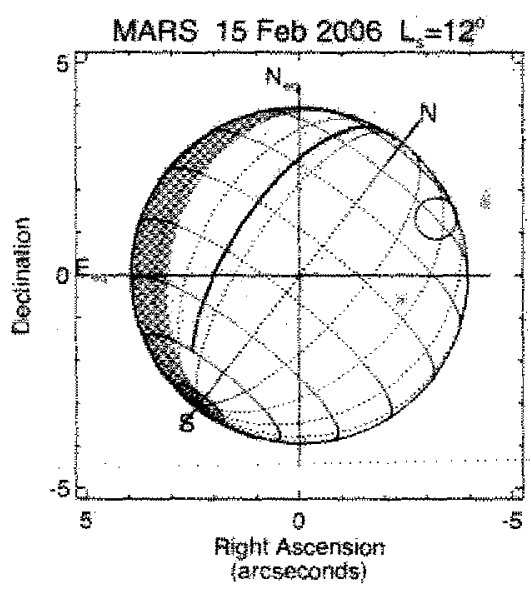

b)

HIPWAC Fob 14-15. SPICAM FOb. 12-18, 2005, L, I2, MYZ8

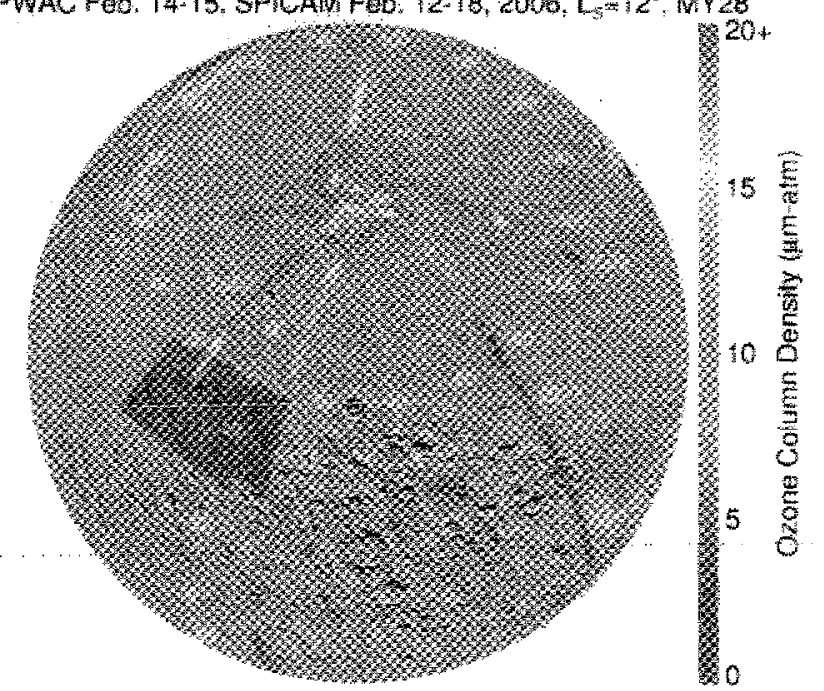

Figure 6: a) Observing geometry for Mars during Feb. 2006 HIPWAC observations at $L_{S}=12^{\circ}$ (early northern spring) which were targeted for a purpose other than direct comparison. The $-8: 00$ path of SPICAM nadir observations is shown as a solid line (asterisk=subsolar point). b) HIPWAC and SPICAM ozone retrievals displayed over MGS MOLA topographical image. Individual colored regions show HIPWAC observational coverage and retrieved average ozone column abundance (14-15 Feb. 2006). Colored tracks show ozone column abundances retrieved by SPICAM during Mars Express orbital passes (12-18 Feb. 2006). 